\title{
Prevalence of Essential Tremor in Araihazar, Bangladesh: A Population-Based Study
}

\author{
Elan D. Louis ${ }^{\text {a-d }}$ Danella Hafeman ${ }^{g}$ Faruque Parvez $^{\mathrm{e}}$ Roy N. Alcalay ${ }^{\mathrm{b}}$ \\ Tariqul Islam ${ }^{\mathrm{i}}$ Abu Baker Siddique ${ }^{\mathrm{i}}$ Tajul Islam Patwary ${ }^{\mathrm{i}}$ Stephanie Melkonian ${ }^{\mathrm{h}}$ \\ Maria Argosh $^{\text {h }}$ Diane Levy ${ }^{f}$ Habibul Ahsan ${ }^{\text {h }}$ \\ ${ }^{a}$ GH Sergievsky Center, ${ }^{b}$ Department of Neurology and 'Taub Institute for Research on Alzheimer's Disease \\ and the Aging Brain, College of Physicians and Surgeons, and Departments of ${ }^{\mathrm{d} E p i d e m i o l o g y,}{ }^{\mathrm{e} E n v i r o n m e n t a l}$ \\ Health Sciences and ${ }^{\mathrm{f} B i o s t a t i s t i c s, ~ M a i l m a n ~ S c h o o l ~ o f ~ P u b l i c ~ H e a l t h, ~ C o l u m b i a ~ U n i v e r s i t y, ~ N e w ~ Y o r k, ~ N . Y ., ~}$ \\ gDepartment of Psychiatry, University of Pittsburgh, Pittsburgh, Pa., and h Department of Health Studies \\ and Cancer Research Center, University of Chicago, Chicago, III., USA; i Columbia University/University of \\ Chicago Arsenic Research Office in Bangladesh, Dhaka, Bangladesh
}

\section{Key Words}

Essential tremor, prevalence $\cdot$ Movement disorders ·

Bangladesh $\cdot$ Population-based study

\begin{abstract}
Background: Essential tremor (ET) is one of the most common neurological diseases. Few prevalence studies have been conducted in South Asia, and none in Bangladesh, one of the most populated countries in the world. We estimated the prevalence of ET in a population-based study in Araihazar, Bangladesh. Methods: As part of an in-person evaluation in a health outcomes study, each study participant produced 2 handwriting samples, from which ET diagnoses were assigned by 2 independent movement disorder neurologists. Results: The crude prevalence of ET (age $\geq 18$ years) was 19/1,229 [1.5\%, 95\% confidence interval $(\mathrm{Cl})=1.0$ $2.4]$, and was similar in men and women. The crude prevalence was $2.5 \%$ in participants aged $\geq 40$ years and was one half that (1.3\%) among younger participants ( $<40$ years), although the difference did not reach statistical significance
\end{abstract}

( $p=0.18)$. The age-adjusted prevalence (United States 2000 census) was $2.0 \%(95 \% \mathrm{Cl}=1.2-2.8)$. Conclusion: The crude prevalence of ET in Araihazar, Bangladesh, was 1.5\%. There is 1 other population-based study in a developing country (Turkey) which, like ours, did not restrict enrollment to middle-aged or elderly individuals and did not rely on screening questionnaires; the crude prevalence in the 2 studies is very similar.

Copyright $\odot 2011$ S. Karger AG, Basel

\section{Introduction}

Essential tremor (ET) is one of the most common neurological diseases [1-4]. Of the 28 population-based prevalence studies, the vast majority have been conducted in North America, Europe or the Middle East [1, 4]. Few have been conducted in Asia [5-9] and even fewer in South Asia [6,7], despite the high proportion of the world's population that resides on that subcontinent. Of the 2 prior studies in South Asia, both in India [6, 7], 1

\section{KARGER}

Fax +41613061234 E-Mail karger@karger.ch www.karger.com
(C) 2011 S. Karger AG, Basel

Accessible online at:

www.karger.com/ned
Dr. Elan Louis

Unit 198, Neurological Institute

710 West 168th Street

New York, NY 10032 (USA)

Tel. +1 212305 9194, Fax +1 212305 1304, E-Mail EDL2@ columbia.edu 
limited its sample to participants aged 60 years and older [6] and both used 2-phase evaluations that involved initial screening questionnaires [6, 7]. Screening questionnaires for ET have been shown to have very low sensitivity (e.g. only $15 \%$ sensitivity for cases with mild ET and 73\% for moderate or severe ET) [10]; this is due to the high prevalence of asymptomatic tremor among affected persons [11]. No prevalence studies of ET have been conducted in Bangladesh, which is among the most populated countries in the world. The current study of persons aged 18 and older in Araihazar, Bangladesh, did not rely on screening questionnaires but rather, as part of an in-person evaluation, each participant produced handwriting samples, from which ET diagnoses were carefully assigned by 2 independent movement disorder neurologists.

\section{Methods}

\section{Study Population and Sampling Frame}

The Health Effects of Arsenic Longitudinal Study is a prospective study of health outcomes associated with arsenic exposure through drinking water in a cohort of adults in Araihazar, Bangladesh, a rural area east of Dhaka with relatively homogenous sociocultural characteristics [12-15]. Between October 2000 and May 2002, we recruited individuals aged 18 and older who were (1) married, (2) residents of the study area for $\geq 5$ years and (3) primarily drinking water from a local well. Using a precohort survey, we enumerated a total of 65,876 individuals residing in Araihazar, from which we identified a sampling frame of 14,828 eligible residents. Of these $14,828,2,778$ were not at home during any of the 3 attempted recruiting visits. Of the 12,050 remaining eligible residents, 11,746 (97.5\%) were enrolled in the Health Effects of Arsenic Longitudinal Study cohort [12-15]. Follow-up evaluations were conducted as follows: follow-up 1 (September 2002 to May 2004), follow-up 2 (June 2004 to August 2006) and follow-up 3 (January 2007 to February 2009).

\section{In-Person Evaluations}

As part of the baseline and follow-up evaluations, 6 medical doctors, who were assisted by trained field staff, collected demographic and medical history data, including medications. This study was approved by the Columbia University Medical Center Internal Review Board and the Bangladesh Medical Research Council, and informed consent was obtained in Bengali from all participants $[12,13]$.

\section{Assessment of Tremor}

A pilot study of the feasibility of spiral drawing was conducted over a 10-day period in February 2005 [12]. Each of 100 consecutively enrolled participants was asked to use their dominant hand to draw an Archimedean spiral. As described [12], spirals were drawn freely on a blank, standard $8.5 \times 11$ inch sheet of paper using a ballpoint pen while the participant was seated at a table. The paper was centered at right angles (horizontally) di- rectly in front of them and held down by their other hand. Participants started at the center of the page, without lifting their pen. This was repeated with the nondominant hand, yielding 2 spirals [12]. Each spiral was later rated by a blinded neurologist who specializes in movement disorders (E.D.L.). The neurologist used an ordinal clinical rating scale from 0 to 3 (including ratings of $0,0.5,1,1.5,2$ and 3) [12]. All 100 participants were able to complete the spiral drawings with no difficulty, indicating the feasibility of spiral drawing in the study setting. One week later, the same neurologist used the identical protocol to rerate the spirals. Spiral scores obtained from the 2 ratings were similar $(\mathrm{r}=0.96 ; \mathrm{p}<0.0001)$, indicating that the ratings were reliable [12]. Of additional importance is that the pilot results failed to detect any association between urinary arsenic levels and tremor severity [12].

The second follow-up evaluation began in June 2004. In January 2006, the spiral drawing protocol was instituted. Each participant evaluated after that point was asked to draw 2 spirals, as described above. Although 2,745 consecutive participants drew spirals, $2(0.07 \%)$ participants were missing 1 of the spirals, leaving 2,743 participants with a complete set of 2 spirals. These 2 spirals were rated by a blinded neurologist who specializes in movement disorders (E.D.L.). During the evaluation, participants were also specifically asked whether they had been diagnosed with Parkinson's disease (PD) and each participant was also asked about their use, on the day of the evaluation, of each of the following substances: betel quids (number of quids chewed that day), tea (number of cups consumed), cigarettes (number of cigarettes smoked), caffeinated soda (number of bottles consumed), and asthma inhalers (number of inhaler puffs), each of which may produce or exacerbate tremor [12]. For religious reasons, ethanol is not consumed in the study area; similarly, coffee drinking is an extremely rare practice in this rural setting in Bangladesh.

\section{Diagnosis of ET}

As in our prior prevalence study in New York [1], ET diagnosis was based on a detailed examination of handwriting samples. Bain et al. [16,17] devised a 10-point scale to grade tremor [from 0 (none) to 10 (severe)]. They also assessed 100 healthy control subjects aged 3-80, noting that $95 \%$ of these controls drew spirals of grade 1 or less $[16,17]$. Their diagnostic criteria for ET specified that the severity of the tremor in ET had to be at least twice the severity seen by the $95 \%$ percentile of normal controls; hence tremor in ET had to be grade 2 or higher $[16,17]$. Their grade 2 spiral rating is the visual equivalent to our rating of 1 . To ensure that our ET diagnoses were assigned in a conservative manner, we instituted the following 2 measures. First, we began with a preliminary diagnosis of ET, reserving this diagnosis only for participants with our tremor rating of 1.5 or higher in either hand (equivalent to grade 3 or higher in the 10-point scale of Bain et al. [16, 17]). One hundred and four participants were assigned a preliminary ET diagnosis; however, 3 were removed because they reported a diagnosis of $\mathrm{PD}$. This method of diagnosing ET is reasonably robust. This was tested in an epidemiological study in New York [18] that enrolled 374 ET cases and 416 controls. We found that the agreement between this method of diagnosing ET (tremor rating of 1.5 or higher in either hand on spiral drawing) and the more detailed, gold standard diagnostic method [examination and rating of postural tremor in each arm and examina- 
Table 1. Characteristics of study participants

\begin{tabular}{|c|c|c|}
\hline & $\begin{array}{l}\text { Initial sample } \\
(\mathrm{n}=2,743)\end{array}$ & $\begin{array}{l}\text { Participants who were not } \\
\text { exposed to medications or } \\
\text { tremor-inducing chemicals } \\
(\mathrm{n}=1,229)\end{array}$ \\
\hline \multicolumn{3}{|l|}{ Age, years } \\
\hline Mean \pm SD & $36.4 \pm 10.0$ & $32.0 \pm 8.7$ \\
\hline Range & $18-70$ & $18-63$ \\
\hline Median & 35.0 & 30.0 \\
\hline Female gender & $1,644(59.9)$ & $959(78.0)$ \\
\hline $\begin{array}{l}\text { Had used a tremor-inducing chemical }{ }^{2} \text { on } \\
\text { the day of the evaluation }\end{array}$ & $1,420(51.8)$ & $0(0)$ \\
\hline Taking any medication ${ }^{3}$ & $225(8.2)$ & $0(0)$ \\
\hline
\end{tabular}

Figures in parentheses indicate percentages.

${ }^{1}$ No use on the day of examination of betel quid, tea, cigarettes, caffeinated soda, asthma inhaler or any medication. ${ }^{2}$ Betel quid, tea, cigarettes, caffeinated soda, asthma inhaler. ${ }^{3}$ Including prescription as well as over-the-counter preparations.

tion and rating of kinetic tremor during 5 tests in each arm (finger-nose-finger maneuver, pouring, using a spoon, drinking, drawing a spiral) followed by the assignment of published diagnostic criteria for ET that required moderate or greater amplitude kinetic tremor on 3 or more tests or head tremor, in the absence of PD or dystonia [10]] was substantial (percentage agreement = $87.2 \%$ and kappa statistic $=0.74$ ). Second, to ensure that our ET diagnoses were assigned in a conservative manner, we required that a second movement disorder neurologist (R.N.A.) independently confirm the diagnoses using an additional set of diagnostic criteria. Hence, this neurologist, blinded to all clinical information and prior ratings, reviewed the spirals from the remaining 101 participants, along with a random sample of spirals from 50 participants without preliminary ET diagnoses. He assigned a final ET diagnosis only to those participants who fulfilled the diagnostic criteria for ET that were proposed in the Consensus Statement on Tremor by the Movement Disorder Society (bilateral, largely symmetric postural or kinetic tremor involving hands and forearms that is visible and persistent) [19]. Sixty-four (63.4\%) of the 101 with preliminary diagnoses of ET were assigned final diagnoses of ET; none $(0.0 \%)$ of the 50 participants without preliminary diagnoses of ET were assigned final diagnoses of ET.

\section{Statistical Analyses}

For the entire sample of 2,743 participants, crude prevalence was reported. Medications and other exposures may exacerbate or produce tremor. Hence, for the remainder of analyses, we conservatively focused on the 1,229 participants who did not take any medications and who, on the day of assessment, were free of exposure to caffeinated beverages (tea, soda), betel nuts, inhalers, and smoking. For these 1,229 participants, crude prevalence and crude prevalence by decade were reported; each point estimate included a $95 \%$ confidence interval (CI). An age-adjusted prevalence was calculated, using direct standardization to the United States population (2000 census data) [20].

Essential Tremor in Bangladesh

\section{Results}

The characteristics of the 2,743 participants with complete spirals are shown in table 1 , indicating a population that was young and largely free of medication. Twentytwo $(0.80 \%)$ reported a diagnosis of $\mathrm{PD}$. The crude prevalence of ET was $64 / 2,743(2.3 \%, 95 \%$ CI $=1.8-3.0)$; none of the $64 \mathrm{ET}$ cases reported a diagnosis of PD.

After removing 1,514 participants who were taking any medication or who had used tremor-exacerbating chemicals on the day of the evaluation [caffeinated beverages (tea, soda), betel nuts, inhalers, smoking], the crude prevalence of ET was 19/1,229 (1.5\%, 95\% CI $=1.0-2.4)$ (fig. 1,2). All further analyses were performed on this smaller, more selected sample of 1,229 participants (tables 1,2$)$. Crude prevalence was similar in men and women (table 2). Crude prevalence was 2.5\% (6/240) among participants aged 40 and older and approximately one half that $(1.3 \%, 13 / 989)$ among younger participants $(<40$ years), although the difference did not reach statistical significance $\left(\chi^{2}=1.78, \mathrm{p}=0.18\right)$. After age adjustment to the United States population (2000 census), the prevalence was $2.0 \%(95 \% \mathrm{CI}=1.2-2.8)$.

\section{Discussion}

No prior studies of the prevalence of ET have been conducted in Bangladesh, despite its being among the most populated countries in the world. We assessed par- 


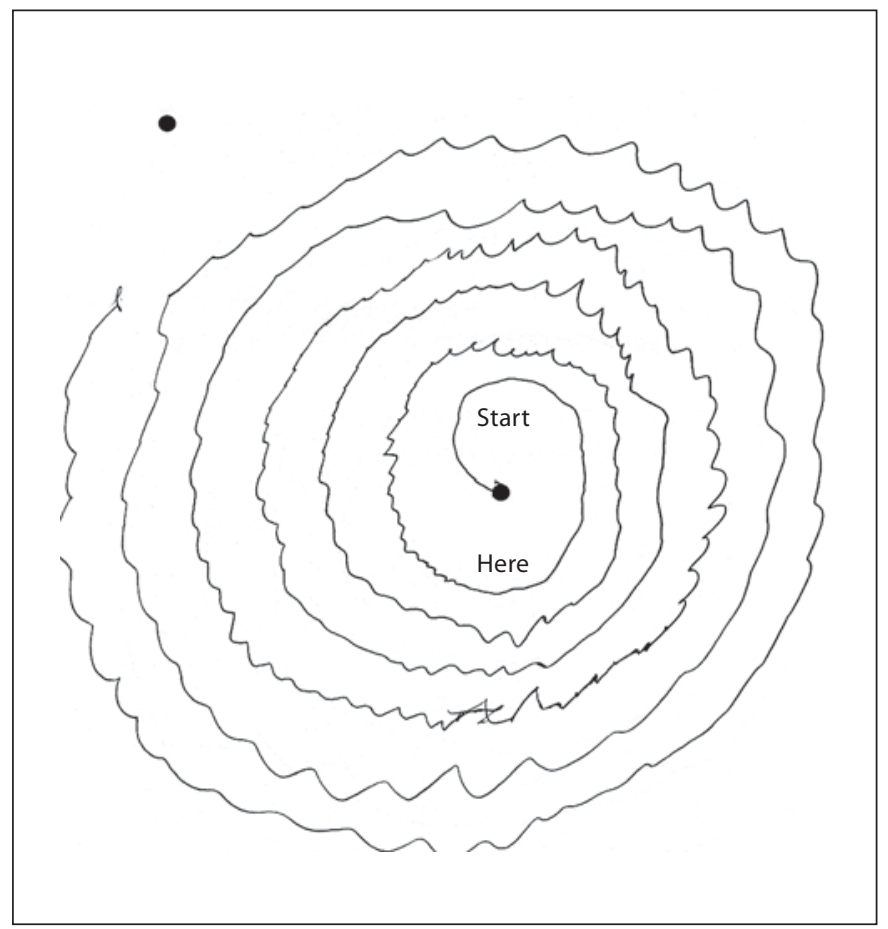

Fig. 1. Archimedean spiral of a participant diagnosed with ET. Oscillations are apparent as the participant attempts to execute the spiral drawing.

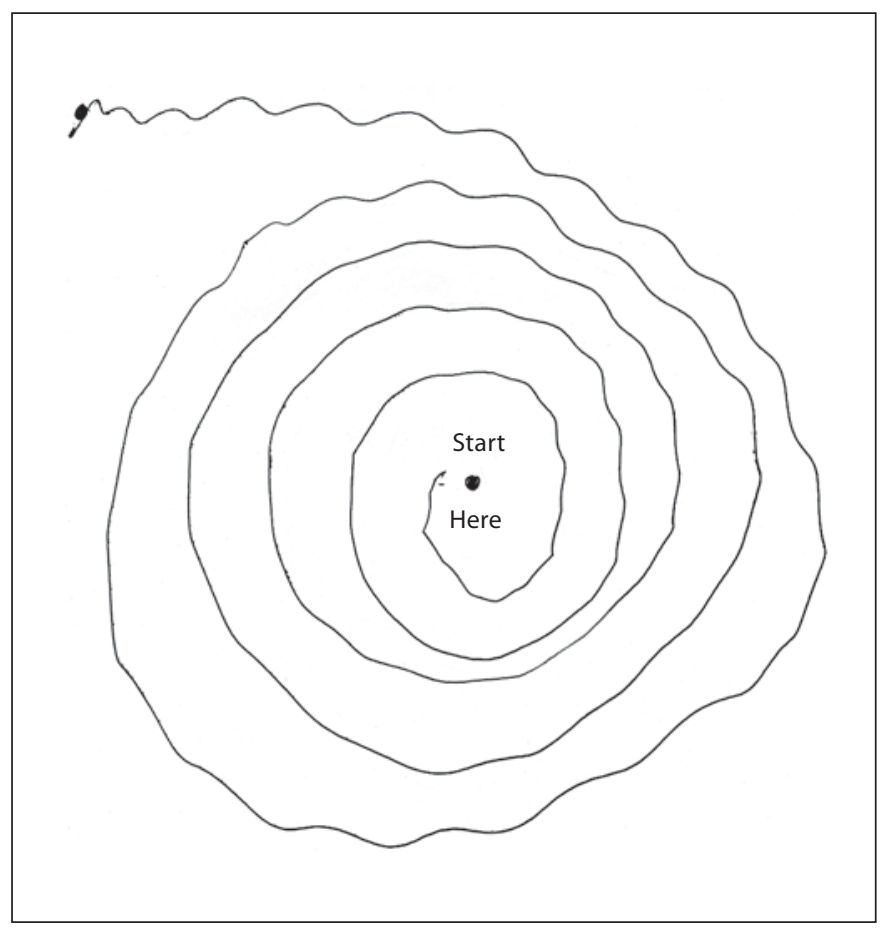

Fig. 2. Archimedean spiral of a second participant diagnosed with ET. Oscillations are apparent in this ET case as well.
Table 2. Crude and age-adjusted prevalence of ET in 1,229 participants who were not exposed to medications or tremor-inducing chemicals ${ }^{1}$

\begin{tabular}{ll}
\hline Prevalence per 100 & $\begin{array}{l}\text { Proportion with ET } \\
\text { (point estimate, 95\% CI) }\end{array}$ \\
\hline Crude prevalence & \\
Total & $19 / 1,229(1.5 \%, 1.0-2.4)$ \\
Men & $3 / 270(1.1 \%, 0.4-3.2)$ \\
Women & $16 / 959(1.7 \%, 1.0-2.7)$ \\
Crude prevalence by age group & \\
$18-19$ years & $0 / 19(0.0 \%)$ \\
$20-29$ years & $8 / 532(1.5 \%, 0.8-2.9)$ \\
$30-39$ years & $5 / 438(1.1 \%, 0.5-2.6)$ \\
$40-49$ years & $5 / 184(2.7 \%, 1.2-6.2)$ \\
$\geq 50$ years & $1 / 56(1.8 \%, 0.4-9.4)$ \\
Age-adjusted prevalence & $(2.0 \%, 1.2-2.8)$ \\
\hline
\end{tabular}

${ }^{1}$ No use on the day of examination of betel quid, tea, cigarettes, caffeinated soda, asthma inhaler or any medication.

${ }^{2}$ After age adjustment to the United States population (2000 census).

ticipants independent of a screening questionnaire in order to obtain a more complete estimate of ET prevalence. Prior population-based studies have shown that evaluation of handwriting for tremor allows investigators to ascertain $85 \%$ [21] or more [22] of all ET cases. After taking the conservative step of removing all participants who had used tremor-exacerbating chemicals on the day of the evaluation or who were taking any medication, we estimated a crude prevalence of ET in Araihazar, Bangladesh, of $1.5 \%(95 \% \mathrm{CI}=1.0-2.4)$.

There have been 2 prior population-based prevalence studies of ET in South Asia [6, 7]. In a study of the geriatric population of Kolkata, India [6], ET was defined using criteria proposed in the Consensus Statement on Tremor by the Movement Disorder Society [19]; crude prevalence (age $\geq 60$ years) was $1.5 \%(95 \% \mathrm{CI}=1.1-2.1)$. That study used an initial screening questionnaire, so that this estimate of prevalence is likely to be low [6]. In a study of the Parsi community of Bombay, India, investigators similarly used a screening questionnaire followed by a neurological examination to assess ET [7]. The age distribution of that population was older than the general Indian population (e.g. $44 \%$ of the sample was $>50$ years of age) and older than ours $(1.8 \%$ of our final sample of 1,229 was $\geq 50$ ). The crude prevalence of ET (all ages) was 1.6\% [7]. The crude prevalence of ET in our sample (age $\geq 18$ ), which did not use an initial screening questionnaire, was 
$1.5 \%(95 \% \mathrm{CI}=1.0-2.4)$. Because of age differences in the populations sampled and methodological differences, it is difficult to compare these 3 studies with one another.

There has been 1 prior population-based study in a developing country that, like ours, did not rely on screening questionnaires and enrolled individuals aged 18 and older (i.e., it did not restrict enrollment to the middleaged or elderly) [23]. In that study [23], the crude prevalence among persons aged 18-50 (the approximate age structure of our sample) was $12 / 1,119(1.1 \%, 95 \% \mathrm{CI}=$ 0.6-1.9), which is similar to that which we report here.

Our study suggested that the prevalence of ET was higher in older age groups, although the difference did not attain significance. The majority of population-based prevalence studies report that the prevalence of ET increases with age, and especially with advanced age [4]. The prevalence of ET was similar in males and females in our study. A recent review indicated that in 11 (61.1\%) of the 18 population-based prevalence studies with adequate data, there was no gender difference in ET prevalence; $6(35.3 \%)$ found a statistically higher prevalence among men, and $1(5.9 \%)$ showed a statistically higher prevalence among women [4].

This study has limitations. First, participants were asked whether they had been diagnosed with PD; given the limited access to care in this rural area, it is possible that some cases of PD were undiagnosed. We do not think this represents a major issue. The prevalence of PD was $0.80 \%$, which is similar to or even higher than that reported in other populations with this age structure (e.g. $0.01 \%$ in Nigeria [24], $0.03 \%$ in India [25] and $0.04 \%$ in China [8]) suggesting that we missed few PD cases. It is even plausible that, given a relatively low level of education, some participants misreported an ET diagnosis as a diagnosis of $\mathrm{PD}$, causing us to overestimate the prevalence of PD and underestimate the prevalence of ET. Second, it is possible that some of the putative ET cases had action tremor due to PD rather than ET. We think this is unlikely. The 2 movement disorder neurologists were careful to examine the spirals for evidence of micrographia and did not assign final diagnoses of ET if micrographia was present. Also, for reasons noted above, we think it is unlikely that we underestimated the prevalence of PD. The third limitation is as follows. Given the reliance on handwriting samples for establishing ET diagnoses, misclassification is certainly possible; nevertheless, this is likely to have resulted in lower (more conservative) estimates of disease prevalence as we may have underascertained ET cases whose major manifestation was head tremor or whose limb tremor was not apparent during spiral drawing. In a previous population-based study of ET, we observed that $15.5 \%$ of ET cases had no tremor while drawing one spiral with their dominant arm [21]. Similarly, Dogu et al. [22] observed this value to be $12.4 \%$. Even if the actual prevalence of ET were $15 \%$ higher than that which we estimated (i.e., 1.7 rather than $1.5 \%$ ), the results are similar (i.e., a $0.2 \%$ difference). On the other hand, we may have overestimated the prevalence of tremor. First, we may also have included some cases of primary writing tremor [26]; however, this entity is rare (by one estimate its prevalence was $1 / 200$ th that of ET) [27], and this would not have been a major source of misclassification. Second, there is dystonic tremor, which may be difficult to distinguish from ET based on a spiral alone. The prevalence of primary dystonia is low in population-based and record-linkage-based studies, with values ranging from 0.003 to $0.03 \%$ [28] (i.e., dystonic tremor would have accounted for far less than 1 of our 64 ET cases). Third, there is the possibility of hyperthyroid tremor. Again, the prevalence in populationbased registries is approximately $1 \%$ [29], meaning that less than 1 of our 64 ET cases is expected to have had hyperthyroidism. Fourth, while enhanced physiologic tremor is a possibility, the careful exclusion of 1,514 participants who were taking any medication or who had used tremor-exacerbating chemicals on the day of the evaluation [caffeinated beverages (tea, soda), betel nuts, inhalers, smoking] very much restricted this possibility as well. Furthermore, as shown by Bain and Findley [16] in a study that enrolled 100 healthy controls, the use of a tremor rating of 1.5 or higher greatly lessened the likelihood of misdiagnosing normal tremor as ET.

The study has several strengths. First, it was a population-based study. Clinic-based studies greatly underestimate the prevalence of ET, with as few as $0.5 \%$ of population-dwelling cases presenting for treatment [30]. Second, as in only 2 prior population-based studies in the world [31,32], our study did not rely on screening questionnaires and sampled adults of all ages. Third, our diagnostic method was conservative as we used cutoffs for tremor severity that were more rigorous than suggested $[16,17]$, required diagnostic input from 2 independent movement disorder neurologists, and limited our final sample to participants who were not taking medications and were free of relevant chemical exposures.

The crude prevalence of ET among individuals aged $\geq 18$ years in this region of Bangladesh was $1.5 \%$. There is 1 prior population-based study in a developing country (Turkey) which opened enrollment to all adults (i.e., it did not limit enrollment to middle-aged or elderly people) and also used a similar methodology (i.e., it did not rely 
on screening questionnaires, which have low sensitivity). These 2 studies reported similar prevalence estimates for ET (1.1-1.5\%), and underscore the frequent occurrence of this neurological condition within human populations. research was also supported by National Institutes of Health Grants P42 ES10349, R01 CA107431 and R01 CA102484. We would like to thank our staff, field workers and study participants in Bangladesh without whom this work would have been impossible.

\section{Acknowledgements}

Elan D. Louis was funded by R01 NS39422 and P30 ES09089

from the National Institutes of Health (Bethesda, Md., USA). This

\section{Disclosure Statement}

The authors declare that there are no conflicts of interest and no competing financial interests.

\section{References}

1 Louis ED, Thawani SP, Andrews HF: Prevalence of essential tremor in a multiethnic, community-based study in northern Manhattan, New York, N.Y. Neuroepidemiology 2009;32:208-214.

-2 Benito-Leon J, Bermejo-Pareja F, Morales JM, Vega S, Molina JA: Prevalence of essential tremor in three elderly populations of central Spain. Mov Disord 2003;18:389-394.

-3 Dogu O, Sevim S, Camdeviren H, Sasmaz T, Bugdayci R, Aral M, Kaleagasi H, Un S, Louis ED: Prevalence of essential tremor: doorto-door neurologic exams in Mersin province, Turkey. Neurology 2003;61:1804-1806.

4 Louis ED, Ferreira JJ: How common is the most common adult movement disorder? Update on the worldwide prevalence of essential tremor. Mov Disord 2010;25:434-541.

-5 Tan LC, Venketasubramanian N, Ramasamy V, Gao W, Saw SM: Prevalence of essential tremor in Singapore: a study on three races in an Asian country. Parkinsonism Relat Disord 2005;11:233-239.

-6 Das SK, Biswas A, Roy J, Bose P, Roy T, Banerjee TK, Mukherjee C, Raut DK, Chowdhury A, Hazra A: Prevalence of major neurological disorders among geriatric population in the metropolitan city of Kolkata. J Assoc Physicians India 2008;56:175-181.

-7 Bharucha NE, Bharucha EP, Bharucha AE, Bhise AV, Schoenberg BS: Prevalence of essential tremor in the Parsi community of Bombay, India. Arch Neurol 1988;45:907908.

-8 LiSC, Schoenberg BS, Wang CC, Cheng XM, Rui DY, Bolis CL, Schoenberg DG: A prevalence survey of Parkinson's disease and other movement disorders in the People's Republic of China. Arch Neurol 1985;42:655-657.

9 Liu HC, Wang SJ, Fuh JL, Liu CY, Lin KP, Lin $\mathrm{CH}$, Wang PN, Lin KN, Wang HC, Chen HM, Chang R, Larson EB, Wu GS, Chou P, Teng EL: The Kinmen Neurological Disorders Survey (KINDS): a study of a Chinese population. Neuroepidemiology 1997;16:60-68.

10 Louis ED, Ford B, Lee H, Andrews H: Does a screening questionnaire for essential tremor agree with the physician's examination? Neurology 1998;50:1351-1357.

11 Louis ED, Ford B, Pullman SL: Prevalence of asymptomatic tremor in relatives of patients with essential tremor. Arch Neurol 1997;54: 197-200.

12 Hafeman D, Ahsan H, Islam T, Louis E: Betel quid: its tremor-producing effects in residents of Araihazar, Bangladesh. Mov Disord 2006;21:567-571.

13 Ahsan H, Chen Y, Parvez F, Argos M, Hussain AI, Momotaj H, Levy D, van Geen A, Howe G, Graziano J: Health Effects of Arsenic Longitudinal Study (HEALS): description of a multidisciplinary epidemiologic investigation. J Expo Sci Environ Epidemiol 2006;16:191-205.

14 Parvez F, Chen Y, Argos M, Hussain AZ, Momotaj H, Dhar R, van Geen A, Graziano JH, Ahsan H: Prevalence of arsenic exposure from drinking water and awareness of its health risks in a Bangladeshi population: results from a large population-based study. Environ Health Perspect 2006;114:355-359.

15 Pierce BL, Kalra T, Argos M, Parvez F, Chen Y, Islam T, Ahmed A, Hasan R, Rakibuz-Zaman M, Graziano J, Rathouz PJ, Ahsan H: A prospective study of body mass index and mortality in Bangladesh. Int J Epidemiol 2010;39:1037-1045.

16 Bain P, Findley LJ: Assessing Tremor Severity. London, Smith-Gordon, 1993.

17 Bain PG, Findley LJ, Thompson PD, Gresty MA, Rothwell JC, Harding AE, Marsden CD: A study of hereditary essential tremor. Brain 1994;117:805-824.

18 Louis ED, Jiang W, Pellegrino KM, Rios E, Factor-Litvak P, Henchcliffe C, Zheng W: Elevated blood harmane (1-methyl-9Hpyrido[3,4-b]indole) concentrations in essential tremor. Neurotoxicology 2008;29: 294-300.

19 Deuschl G, Bain P, Brin M: Consensus statement of the movement disorder society on tremor. Ad hoc scientific committee. Mov Disord 1998;13(Suppl 3):2-23.

20 US Census Bureau: www.Census.Gov/census2000.

21 Louis ED, Ford B, Wendt KJ, Lee H, Andrews $\mathrm{H}$ : A comparison of different bedside tests for essential tremor. Mov Disord 1999;14: 462-467.

-22 Dogu O, Louis ED, Sevim S, Kaleagasi H, Aral M: Clinical characteristics of essential tremor in Mersin, Turkey - A population- based door-to-door study. J Neurol 2005;252: 570-574.

23 Sur H, Ilhan S, Erdogan H, Ozturk E, Tasdemir M, Boru UT: Prevalence of essential tremor: a door-to-door survey in Sile, Istanbul, Turkey. Parkinsonism Relat Disord 2009;15:101-104.

24 Osuntokun BO, Adeuja AO, Schoenberg BS, Bademosi O, Nottidge VA, Olumide AO, Ige O, Yaria F, Bolis CL: Neurological disorders in Nigerian Africans: a community-based study. Acta Neurol Scand 1987;75:13-21.

25 Gourie-Devi M, Gururaj G, Satishchandra P, Subbakrishna DK: Prevalence of neurological disorders in Bangalore, India: a community-based study with a comparison between urban and rural areas. Neuroepidemiology 2004;23:261-268.

26 Klawans HL, Glantz R, Tanner CM, Goetz CG: Primary writing tremor: a selective action tremor. Neurology 1982;32:203-206.

27 Martinelli P, Gabellini AS, Gulli MR, Lugaresi E: Different clinical features of essential tremor: a 200-patient study. Acta Neurol Scand 1987;75:106-111.

28 Papantonio AM, Beghi E, Fogli D, Zarrelli M, Logroscino G, Bentivoglio A, Simone P, Tonali P, Specchio LM: Prevalence of primary focal or segmental dystonia in adults in the district of Foggia, Southern Italy: a service-based study. Neuroepidemiology 2009; 33:117-123.

29 Leese GP, Flynn RV, Jung RT, Macdonald TM, Murphy MJ, Morris AD: Increasing prevalence and incidence of thyroid disease in Tayside, Scotland: the Thyroid Epidemiology Audit and Research Study (TEARS). Clin Endocrinol (Oxf) 2008;68:311-316.

30 Larsson T, Sjogren T: Essential tremor: a clinical and genetic population study. Acta Psychiatr Scand Suppl 1960;36:1-176.

- 31 Salemi G, Savettieri G, Rocca WA, Meneghini F, Saporito V, Morgante L, Reggio A, Grigoletto F, Di Perri R: Prevalence of essential tremor: a door-to-door survey in Terrasini, Sicily. Sicilian Neuro-Epidemiologic Study Group. Neurology 1994;44:6164.

32 Hornabrook RW, Nagurney JT: Essential tremor in Papua, New Guinea. Brain 1976; 99:659-672. 